\title{
Familial hypertriglyceridemia: an entity with distinguishable features from other causes of hypertriglyceridemia
}

Ivette Cruz-Bautista 1,2, Alicia Huerta-Chagoya ${ }^{3,4}$, Hortensia Moreno-Macías 3,5, Rosario Rodríguez-Guillén ${ }^{3}$, María Luisa Ordóñez-Sánchez ${ }^{3}$, Yayoi Segura-Kato ${ }^{3}$, Roopa Mehta ${ }^{1,2}$, Paloma Almeda-Valdés ${ }^{1,2}$, Lizeth Gómez-Munguía ${ }^{1}$, Ximena Ruiz-De Chávez², Ximena Rosas-Flota², Arali Andrade-Amado², Bárbara Bernal-Barroeta², María Guadalupe López-Carrasco², Luz Elizabeth Guillén-Pineda², Angelina López-Estrada2, Daniel Elías-López 1,2, Alexandro J. Martagón-Rosado 1,6, Donají Gómez-Velasco ${ }^{1}$, Cesar Ernesto Lam-Chung ${ }^{2}$, Omar Yaxmehen Bello-Chavolla ${ }^{1,7}$, Fabiola Del Razo-Olvera ${ }^{1,2}$, Lucely D. Cetina-Pérez ${ }^{8}$, José Luis Acosta-Rodríguez ${ }^{9}$, María Teresa Tusié-Luna ${ }^{3}$ and Carlos A. Aguilar-Salinas ${ }^{1,2,6^{*}}$ (D)

\footnotetext{
Abstract

Background: Familial hypertriglyceridemia (FHTG) is a partially characterized primary dyslipidemia which is frequently confused with other forms hypertriglyceridemia. The aim of this work is to search for specific features that can help physicians recognize this disease.

Methods: This study included 84 FHTG cases, 728 subjects with common mild-to-moderate hypertriglyceridemia (CHTG) and 609 normotriglyceridemic controls. All subjects underwent genetic, clinical and biochemical assessments. A set of 53 single nucleotide polymorphisms (SNPs) previously associated with triglycerides levels, as well as 37 rare variants within the five main genes associated with hypertriglyceridemia (i.e. LPL, APOC2, APOA5, LMF1 and GPIHBP1) were analyzed. A panel of endocrine regulatory proteins associated with triglycerides homeostasis were compared between the FHTG and CHTG groups.

Results: Apolipoprotein B, fibroblast growth factor 21(FGF-21), angiopoietin-like proteins 3 (ANGPTL3) and apolipoprotein A-II concentrations, were independent components of a model to detect FHTG compared with CHTG (AUC $0.948,95 \% \mathrm{Cl} 0.901-0.970,98.5 \%$ sensitivity, 92.2\% specificity, $P<0.001$ ). The polygenic set of SNPs, accounted for $1.78 \%$ of the variance in triglyceride levels in FHTG and $6.73 \%$ in CHTG.

(Continued on next page)
}

\footnotetext{
* Correspondence: caguilarsalinas@yahoo.com

${ }^{1}$ Unidad de Investigación de Enfermedades Metabólicas, Instituto Nacional de Ciencias Médicas y Nutrición Salvador Zubirán, Vasco de Quiroga 15,

Tlalpan, 14080 Mexico City, Mexico

${ }^{2}$ Departamento de Endocrinología y Metabolismo, Instituto Nacional de

Ciencias Médicas y Nutrición Salvador Zubirán, Vasco de Quiroga 15, Tlalpan, 14080 Mexico City, Mexico

Full list of author information is available at the end of the article
}

(C) The Author(s). 2021 Open Access This article is licensed under a Creative Commons Attribution 4.0 International License, which permits use, sharing, adaptation, distribution and reproduction in any medium or format, as long as you give appropriate credit to the original author(s) and the source, provide a link to the Creative Commons licence, and indicate if changes were made. The images or other third party material in this article are included in the article's Creative Commons licence, unless indicated otherwise in a credit line to the material. If material is not included in the article's Creative Commons licence and your intended use is not permitted by statutory regulation or exceeds the permitted use, you will need to obtain permission directly from the copyright holder. To view a copy of this licence, visit http://creativecommons.org/licenses/by/4.0/ The Creative Commons Public Domain Dedication waiver (http://creativecommons.org/publicdomain/zero/1.0/) applies to the data made available in this article, unless otherwise stated in a credit line to the data. 
(Continued from previous page)

Conclusions: The clinical and genetic differences observed between FHTG and CHTG supports the notion that FHTG is a unique entity, distinguishable from other causes of hypertriglyceridemia by the higher concentrations of insulin, FGF-21, ANGPTL3, apo A-II and lower levels of apo B. We propose the inclusion of these parameters as useful markers for differentiating FHTG from other causes of hypertriglyceridemia.

Keywords: Familial hypertriglyceridemia, Mexicans, Primary dyslipidemias, Chylomicronemia, FGF-21, ANGPTL3, Apolipoprotein B

\section{Introduction}

Hypertriglyceridemia (HTG) is a common medical condition associated with abnormal very-low-density lipoprotein (VLDL) and chylomicron particle number and composition and in certain cases, is associated with increased cardiovascular risk [1]. According to the European Society of Cardiology and European Atherosclerosis Society, mild-to- moderate HTG is defined by triglycerides levels $>150-880 \mathrm{mg} / \mathrm{dL}$, and severe HTG refers to levels > $880 \mathrm{mg} / \mathrm{dL}[2,3]$. The prevalence of HTG varies among ethnic groups $[4,5]$; it is highly prevalent in Hispanics. In Mexico, the prevalence of mild-to-moderate hypertriglyceridemia is around $31 \%$, with $~ 5 \%$ of the Mexican population showing severe HTG [6].

Familial hypertriglyceridemia (FHTG) is a form of HTG, in which the clinical and genetic spectrum has not been elucidated [7]. FHTG is frequently confused with other causes of HTG. This includes familial chylomicronemia syndrome (FCS) $[8,9]$, a condition caused by mutations in the lipoprotein lipase $(L P L)$ gene or other genes that regulate the function of this enzyme (i.e $A P O C 2$ and the LMF1 (lipase maturation factor 1)) [1014]. This also includes conditions characterized by common mild-to-moderate hypertriglyceridemia (CHTG), such as familial combined hyperlipidemia (FCHL). The diagnosis of this dyslipidemia is suggested by a fluctuating lipid profile, apolipoprotein B (apo B) levels >90th population percentile for age and gender and a firstdegree family history of premature cardiovascular disease [15-17].

FHTG was described by Glueck and co-workers in 1973. It is the most common form of primary isolated hypertriglyceridemia. Its prevalence in Caucasian populations has been estimated to be around $0.5-1 \%$ [18]. In Mexico, the exact prevalence of FHTG is unknown, although it is frequently diagnosed associated with pancreatitis. The inheritance of this disease is autosomal dominant with variable penetrance, however, the genes involved are still largely unknown. A genome-wide association study (GWAS) in the Mexican population, identified genes associated with triglyceride levels in patients with moderate hypertriglyceridemia [19]. As yet, there is no information about the contribution of these genes in FHTG [20]. The principle pathophysiological defect appears to be a deficit in the catabolism of very-low density lipoproteins (VLDLs). The number of particles is relatively stable, but the triglyceride content is increased. Thus, there is an increase in VLDL particle size with no concomitant elevation of apo B concentration [21]. Large VLDL particles are not an optimum substrate for LPL, hence, hydrolysis is slow. A simultaneous decrease in high-density lipoprotein cholesterol (HDL-C) is frequently found. FHTG is characterized by the presence of fasting plasma triglyceride (TG) levels $>95$ th population percentile for age and gender, as well as normal to low total cholesterol levels [18]. Therefore, the biochemical presentation of FHTG is characterized by variable levels of triglycerides (200-700 mg/dL) and the presence of triglyceride rich VLDL particles (hyperlipidemia (HLP) type 4). When FHTG coexists with other comorbidities, such as type 2 diabetes (T2D), the metabolic syndrome (MS), or environmental factors such as increased alcohol intake or a high fat diet [22-26], the levels of triglycerides can reach values of over $1000 \mathrm{mg} / \mathrm{dL}$ with a TG/ cholesterol ratio of 5:1, accompanied by the presence of chylomicrons (HLP type 5). Hence, this condition is associated with a life-threatening risk of acute pancreatitis [27]. The normal apo B levels encountered in FHTG, even when TG levels are below $500 \mathrm{mg} / \mathrm{dL}$ allows it to be distinguised from FCHL [17].. Although, some authors have suggested that FHTG is not different from other oligogenic/polygenic forms of hypertriglyceridemia (e.g. FCHL) [28]. Diagnosis of FHTG is confirmed when the proband and one or more of their family members show a similar lipid pattern $[20,22]$. The atherogenicity of FHTG is a subject of great controversy; Mendelian randomization studies have demonstrated a causal role of the triglyceride and triglyceride-rich particles and their remnants in atherosclerotic cardiovascular disease $[2,29]$.

The aim of this study is to describe the clinical, biochemical and genetic characteristics of FHTG, in order to identify peculiarities which, distinguish this disease from other forms of HTG. A secondary aim is to analyze differences in the circulating levels of regulatory proteins related to triglyceride homeostasis between 171 study subjects, (composed of 84 FHTG individuals and 85 CHTG individuals) and 73 control individuals. These 
regulatory proteins include three members of the secreted Fibroblast Growth Factor (FGF) family of proteins namely fibroblast growth factor 19 (FGF-19) [30], fibroblast growth factor 21(FGF-21) [31] and fibroblast growth factor 23 [32]. FGF-21 regulates hepatocyte and adipocyte metabolism, FGF-19 is a regulator of bile acid synthesis (increased bile acid synthesis is seen in hypertriglyceridemia), and FGF-23 has recently been implicated in cardiovascular risk. The measurement of angiopoietin-like proteins 3 and 4 (ANGPTL-3 and ANGPTL-4) was also carried out. These proteins exhibit functional roles in lipid metabolism and inflammation. They are regulators of lipoprotein and glucose metabolism. ANGPTL-3 function is linked to the inhibition of lipoprotein lipase (LPL) activity, the principal enzyme that hydrolyzes triglycerides [33] and to the activation of lipolysis in adipocytes, a process resulting in FFA and glycerol release into the circulation [33]. ANGPTL-3 is a predictor of peripheral artery disease, associated with endothelial dysfunction, and is thought to stimulate the proliferation of prothrombotic and proinflammatory cells, exacerbating atherosclerosis [33]. The inhibition of ANGPTL3 is a promising pharmacological target for the prevention of coronary artery disease in hypertriglyceridemia especially in persons with FHTG in which the control of triglycerides levels is a challenge. The GalNAc-conjugated ANGPTL3 ASO, targets ANGPTL3 synthesis in the liver, reducing atherogenic lipoproteins. ANGPTL4 is regulated by different nuclear receptors, it is induced by fasting and is produced in liver, muscle, liver and adipose tissue. ANGPTL4 has an important role in fat metabolism and adipose tissue differentiation. The regulation of LPL by ANGPTL4 is important for protection from the proinflammatory effects of lipid accumulation [33].

In addition, the measurement of liver-type fatty acidbinding protein (FABP1/L-FABP), was also included as this protein is associated with dyslipidemia (elevated plasma triglycerides) and non-alcoholic fatty liver disease (NAFLD), a condition commonly seen in FHTG subjects [34]. Finally, the measurement of apolipoproteins including apo A-II and apolipoprotein CIII (apo C-III) was carried out in all subjects [35].

The measurement of these regulatory proteins will permit the detection of a set of variables that better identify FHTG cases.

\section{Material and methods}

\section{Study participants}

A total of 1421 subjects were stratified into 3 groups according to triglyceride levels. Two of the groups were prospectively enrolled over a twelve-month period (January to December 2019) from the lipid clinic of the Instituto Nacional de Ciencias Médicas y Nutrición Salvador
Zubirán (INCMNSZ). The initial consultation included a medical history, physical examination and fasting blood samples for biochemical measurements (lipid profile, glucose, thyroid function, renal and hepatic function tests) and DNA extraction. All subjects signed informed consent on entering the study. The study protocol conformed to the ethical guidelines of the 1975 Declaration of Helsinki and was approved by the Research and Ethics Committee of the hospital. The 3 groups of subjects were: 1) eighty-four unrelated cases with FHTG defined as TG levels $\geq 1000 \mathrm{mg} / \mathrm{dL}(\geq 11.3 \mathrm{mmol} / \mathrm{l})$ on at least one occasion, with apo B levels <90th population percentile for age and gender and a 5:1 TG/cholesterol ratio, after excluding other causes of HTG [22]. The study subject had to have at least one first-degree relative with the same lipid patterns. 2) a group pf 728 subjects with CHTG defined as TG levels $\geq 150 \mathrm{mg} / \mathrm{dL}$ but $<600 \mathrm{mg} /$ $\mathrm{dL}$ ( $>2.26$ but $<6.78 \mathrm{mmil} / \mathrm{l})$, low-density lipoprotein cholesterol (LDL-C) levels $<190 \mathrm{mg} / \mathrm{dL}(<4.921 \mathrm{mmol} / \mathrm{l})$ estimated by Martin and Sampson formulas [36, 37], and 3) 609 individuals from the UNAM-INCMNSZ Diabetes Study, who participated in the SIGMA T2D Consortium [38] and met the eligibility requirements for normotriglyceridemic controls. These subjects had normal fasting TG levels $<150 \mathrm{mg} / \mathrm{dL}(1.7 \mathrm{mmol} / \mathrm{l})$ and normal HDL-C levels $(40-60 \mathrm{mg} / \mathrm{dL}, 1.04-1.56 \mathrm{mmol} / \mathrm{l})$. For the analysis of the metabolic profile, all 84 FHTG were included plus subgroups of 85 CHTG and 73 control individuals for whom serum samples were available. Subgroups were matched by gender, body mass index (BMI) and waist circumference to permit comparisons among groups. However, adjustment for age was necessary.

Exclusion criteria included pregnancy, alcoholism (defined as the consumption of at least 10 alcoholic beverages within a 2-month period), uremia (serum creatinine $>176.8 \mu \mathrm{mol} / \mathrm{l})$, nephrotic syndrome, hemodialysis, severe liver failure, lipid-lowering drugs, HIV infection, acute stress events in the 6 weeks before entering the study, untreated thyroid disease or other autoimmune diseases and an FCS score $\geq 10$ [8].

\section{Anthropometric measurements}

Anthropometric measurements included weight and height estimations with calibrated scales and stadimeters. Waist-circumference was measured at the midpoint between the lower border of the costal margin and the iliac crest during exhalation. Arterial hypertension was defined as a systolic blood pressure $(\mathrm{SBP}) \geq 140$ $\mathrm{mmHg}$, diastolic blood pressure (DBP) $\geq 90 \mathrm{mmHg}$ or self-reported use of antihypertensive medications [39]. Smoking status was recorded and individuals were classified as current smokers (smoking at least one cigarette in the previous month), former smokers (smoking the 
last cigarette more than 6 months ago) or never smokers.

\section{Biochemical measurements}

All measurements were performed after a 12-h fast. Samples were taken by venous puncture and distributed into tubes BD Vacutainer ${ }^{\circ}$ RST and were immediately stored on ice until clot was formed and centrifuged at $1500 \mathrm{rpm}$ for $15 \mathrm{~min}$. Glucose, total cholesterol and HDL-C measurements were performed using Synchron CX Delta (Beckman Coulter) colorimetric enzymatic methods and apo B measurements were performed by nephelometry (Beckman Coulter). The homeostasis model assessment for insulin resistance (HOMA2-IR) was calculated using the HOMA2 calculator released by the Diabetes Trials Unit, University of Oxford, available at: http://www.dtu.ox.ac.uk/homacalculator/index.php. Leptin and adiponectin were measured using ELISA (Millipore microplates). FGF-21, FGF-19, FGF-23, ANGPTL3, 4, apo C-III were measured by MILLIPLEX ${ }^{\circ}$ MAP, according to the manufacturer's protocols.

\section{DNA purification and SNP genotyping}

Genomic DNA was extracted from whole blood using the QIAmp 96 DNA Blood Kit. Purity and concentration were obtained with a NanoDrop ND 1000. DNA samples were genotyped at LGC Genomics (Beverly, MA, USA) using KASP genotyping technology, which is a competitive allele-specific PCR that enables highly accurate biallelic scoring of SNPs. On a first PCR round, it uses three assay-specific non-labelled primers: one common reverse primer plus two allele-specific forward primers. On a second PCR round, a fluorescent signal is generated using fluor-labelled FRET cassettes. SNPs with a call rate $<97 \%$ were considered technical failures and were automatically removed before further quality control.

\section{Variants selection criteria and quality control procedure}

Two sets of markers were genotyped. The first one was selected to explore the polygenic component of TG levels and included 53 common tag SNPs, one per gene, previously associated to TG levels, as reported by Willer et al. and Weissglass-Volkov et.al $[19,40]$. The second set of markers was selected to explore the monogenic component and included 37 genetic variants located within the five main genes associated with FCS (i.e. $L P L, A P O C 2$, $A P O A 5, L M F 1$ and GPIHBP1) and consistently found in FCS and FHTG cases [10-14] (Supplementary Tables 1 and 2).

Specifically, for the polygenic component set, quality control included the exclusion of samples with $\geq 10 \%$ missing data within the full dataset or whose call rate between cases and controls was statistically different
$(P<0.00001)$. In addition, variants with $\geq 5 \%$ missing data and monomorphic variants were also removed. All SNPs were tested for Hardy-Weinberg equilibrium $(P<$ 0.000001). SNPs that failed to pass the test were excluded for further analyses. In turn, except for casecontrol call rate difference, minor allele frequency and Hardy-Weinberg equilibrium filters, quality control of the monogenic component set included the same criteria. After quality control, whole dataset included 1421 individuals (84 FHTG cases, 728 CHTG patients and 609 normolipidemic controls), 38 SNPs from the polygenic component set (1 SNP failed HWE test and 14 SNPs were monomorphic) and 37 variants from the monogenic component set.

\section{Statistical analyses}

The distribution of continuous variables was explored using the Kolmogorov-Smirnov test. Data are presented as median and interquartile range. Categorical variables are reported as frequencies and percentages. Continuous variables were compared among FHTG, CHTG and control subjects using the Kruskall-Wallis test, with the Dunn Test post hoc analysis. The frequency distribution of the categorical variables was compared using chisquared test. In order to control for population structure, an ancestry index was calculated through principal components analysis using a validated set of 32 ancestry informative markers for Latino populations [41] via the EIGENSTRAT software [42]. The top 2 principal components (PC) were used as covariates in further analyses.

The genetic association between variants of the polygenic component set with FHTG and CHTG was assessed using logistic regression models. For the first analysis FHTG individuals were the cases and normotriglyceridemic subjects were the controls. Similarly, for the second analysis, CHTG were the cases and normotriglyceridemic subjects were the controls. Models were adjusted for age, age ${ }^{2}$, sex, BMI, T2D status, and the top 2 PCs to account for ancestry. The effect of each variant was assessed separately. Since all variants have already been proved to be associated with TG levels, nominal $p$ values without correction for multiple comparisons are reported. Associations with $P<0.05$ were considered statistically significant. For the variants of the monogenic component set, only allele frequencies among FHTG individuals are reported.

Finally, the TG variance explained specifically by the polygenic set of genetic variants was calculated, as described by Purcell et al., 2007 [43]. Briefly, for each individual, a genetic risk score (GRS) using PLINK software (i.e. number of score alleles weighted by the previously reported beta coefficients in the literature) was estimated. Scores were additive across SNPs. No scores were imputed for missing genotypes. Next, the TG 
variance explained by the GRS as the difference in the $\mathrm{r}^{2}$ from a linear regression model including the score and covariates and a linear regression model excluding the score was calculated. Defined covariates were sex, age, $\mathrm{age}^{2}$, BMI, T2D status, ancestry and the number of nonmissing genotypes used to calculate each GRS. A bootstrapped 97\% confidence interval for R-squared was generated based on 10,000 replications. PLINK software and $\mathrm{R}$ were used for all genetics analyses.

In addition, an analysis of proinflammatory parameters was also carried out to see if they were useful to distinguish between FHTG and CHTG. To evaluate the contribution of additional metabolic parameters to routine clinical measurements support vector machines (SVM) models with the e1071 $\mathrm{R}$ package were constructed, optimizing hyperparameters using cross-validation tuning to assess models comprising the identified pathophysiological components. To estimate performance of SVM models comparing the addition of metabolites, confusion matrices, area under the receiver operating characteristic (ROC) curves (c-statistic) and selected the cut-off value with optimal balance between sensitivity and specificity using the Optimal Cutpoints $\mathrm{R}$ package computing the Youden Index were estimated to evaluate discrimination between FHTG, CHTG and controls [44]. The models were adjusted for age, gender and BMI, apo B and then compared when each additional metabolite was included; thresholds for individual variables were evaluated and clinically useful models for the detection of FHTG compared to CHTG and control subjects using sequential logistic regression models were constructed, assessing model selection using ROC curves and the Bayesian Information Criterion (BIC); the better model had the better AUC of ROC and the lowest BIC. Stata v13.0, SPSS v25.0 and R v3.6.1 were used to perform analyses [45].

\section{Results \\ Clinical and biochemical characteristics of all study subjects}

Table 1 shows the characteristics of the study group, which included 1421 individuals (84 FHTG cases, 728 CHTG individuals, and 609 normotriglyceridemic controls. FHTG subjects were younger compared to the CHTG group, and the FHTG group had a lower proportion of female participants. Not a single FHTG subject met the diagnostic scoring system criteria for FCS $(\geq 10)$ and none had eruptive xanthomas [8]. The prevalence of T2D was higher in FHTG subjects and $20 \%$ had a history of acute pancreatitis. FHTG subjects had lower HDL-C, non-HDL-C and apo B levels $(P<0.001)$ and higher concentrations of insulin, and HOMA IR $(P<$

Table 1 Clinical and biochemical characteristics of study subjects

\begin{tabular}{|c|c|c|c|c|c|}
\hline Variable & Normal Triglycerides & CHTG & FHTG & $\begin{array}{l}P \text { value } \\
\text { ALL }\end{array}$ & $\begin{array}{l}P \text { value* } \\
\text { FHTG vs CHTG }\end{array}$ \\
\hline Sample size & 609 & 728 & 84 & & \\
\hline Sex (\% females) ${ }^{a}$ & 69.2 & 51.1 & 24.4 & $<0.001$ & $<0.001$ \\
\hline Age (years) & 54 [48-63] & 53 [48-60] & $43[37-47.8]$ & $<0.001$ & $<0.001$ \\
\hline BMI $\left(\mathrm{kg} / \mathrm{m}^{2}\right)$ & $27[24.7-30]^{\mathrm{b}}$ & $28.6[25.9-31.6]$ & $28.9[26.1-32.1]$ & $<0.001$ & 0.718 \\
\hline Waist circumference $(\mathrm{cm})$ & $90.8[84.5-98]^{b}$ & 95.4 [89.5-103] & 96 [88-100] & $<0.001$ & 0.581 \\
\hline Triglycerides (mg/ dL) & 113 [88.57-130] & 270 [228-331.25] & $916.46[293.24-1435.44]^{c}$ & $<0.001$ & $<0.001$ \\
\hline Cholesterol (mg/ dL) & 195 [168.52-218.31] & 217 [190-243] & $191.02[163-250.87]^{c}$ & $<0.001$ & 0.027 \\
\hline $\mathrm{HDL}-\mathrm{C}(\mathrm{mg} / \mathrm{dL})$ & $47[42-55]$ & 38 [32-44] & 30.64 [24.89-37.34] & $<0.001$ & $<0.001$ \\
\hline Non- HDL-C (mg/ dL) & $145[121-168]$ & 176 [154-201] & $159[130-216]^{c}$ & $<0.001$ & 0.288 \\
\hline Apo B (mg/ dL) & $103[86-118]$ & 126 [108-143] & 91.8 [82-97.6] & $<0.001$ & $<0.001$ \\
\hline Glucose (mg/ dL) & $90[83-108]^{b}$ & 94 [85-148.25] & 99 [90.5-119] & $<0.001$ & 0.361 \\
\hline Insulin ( $\mu \mathrm{U} / \mathrm{L})$ & $8.3[5.6-12]^{b}$ & 10.35 [7.57-15.7] & $13.3[7.9-18.8]$ & $<0.001$ & 0.036 \\
\hline HOMA2 B\% & $106.2[81.3-139.4]$ & $119.85[92.6-159.7]^{d}$ & $102.2[65.8-154.4]$ & $<0.001$ & 0.002 \\
\hline HOMA IR & $1.06[0.72-1.56]^{b}$ & 1.37 [1.0-2.06] & $1.79[1.17-2.28]$ & $<0.001$ & 0.004 \\
\hline T2D (\%) ${ }^{\mathrm{a}}$ & 31.7 & 39.8 & 25.6 & $<0.001$ & 0.010 \\
\hline AP (\%) & - & - & $20 \%$ & $<0.001$ & $<0.001$ \\
\hline
\end{tabular}

Median [25th percentile-75th percentile] or percentages are shown. AP: Acute pancreatitis

${ }^{a}$ Chi square/Fisher exact test

Kruskall Wallis test for metabolic traits adjusted for age, BMI, triglycerides levels and sex;

${ }^{b}$ post hoc $P<0.01$ by Dunn test: Normal triglycerides subjects different among the other groups

c post hoc $P<0.01$ by Dunn test: FHTG subjects different only from CHTG subjects

${ }^{d}$ post hoc $P<0.01$ by Dunn test: CHTG subjects different among the other groups

*U-Mann Whitney test 
0.001). Supplementary Table 5 shows the data of the patients divided by T2D status.

Pro-atherogenic profile and endocrine regulatory proteins closely related to triglyceride homeostasis

Table 2 shows the comparison between all FHTG cases and a subsample of CHTG and controls. There were no significant differences in BMI, gender and waist circumference between FHTG and CHTG groups; however, the FHTG group was younger $(P=0.005)$. Normal triglyceridemic individuals were younger with lower BMI, so all the comparisons were adjusted for age, gender, BMI and triglycerides levels. FHTG subjects showed lower levels of apo B and leptin levels and significantly higher levels of FGF-21, ANGPTL3, ANGPTL4 compared to CHTG and controls $(P<0.001)$. FHTG individuals showed higher levels of apo A-II compared to CHTG subjects $(P<0.001)$.

All the exploratory biomarkers were useful to distinguish between FHTG, CHTG and controls. The most informative metabolites were FGF-21, apo A-II and ANGP TL3. The ANGPTL3 threshold was > $198 \mathrm{ng} / \mathrm{mL}$ (AUC $0.819,95 \%$ CI $0.761-0.877$ ) with a sensitivity of 0.95 (95\% CI 0.91-0.98) and a specificity of 0.50 (95\% CI 3961 ) to detect FHTG. For FGF-21, the threshold was $>87$ $\mathrm{pg} / \mathrm{mL}$ (AUC 0.788, 95\% CI 0.728-0.848), with a sensitivity of $0.71(95 \%$ CI $0.61-0-.80)$ and a specificity of 0.75 (95\% CI 0.68-0.82). Finally, for apo A-II the threshold was > $0.472 \mathrm{mg} / \mathrm{dL}$ (AUC 0.878, 95\%CI 0.824-0.932), with a sensitivity of $0.86(95 \% \mathrm{CI} 0.76-0.92)$ and a specificity of 0.79 (95\%CI $0.68-0.88)$.

An SVM model was constructed to discriminate FHTG from CHTG and control subjects which included gender, age, BMI and apolipoprotein B levels. The model had an AUC of 0.852 (95\%CI 0.786-0.904, 96.15\% sensitivity, 79.61 specificity). The inclusion of FGF-21, ANGP TL3 and apo A-II together with clinical variables showed the best performance (AUC 0.948, 95\%CI 0.901-0.970, 98.5\% sensitivity, $92.2 \%$ specificity, $P<0.001$ ) of all the explored models (Table 3 ). If T2D subjects were excluded, the model showed an AUC 0.969, (95\%CI 0.9380.999).

In the SVM models, none of the individual clinical variables were as strong as the added predictors and the combination of variables was decidedly superior. Finally, a clinical model was developed to easily identify FHTG using logistic regression analyses. A model comprised of, FGF-21 $>27.0 \mathrm{pg} / \mathrm{mL}$, apo A-II $>0.472 \mathrm{mg} / \mathrm{dL}$, and apo $\mathrm{B}<102 \mathrm{mg} / \mathrm{dL}$, showed the best performance to differentiate FHTG from CHTG; the addition of ANGPTL3 > $214 \mathrm{ng} / \mathrm{mL}$ improved model performance.

Role of the common polygenic TG component with FHTG The role of 53 common SNPs (previously associated with TG levels and CHTG) included in the polygenic component set, were assessed [41-43]. Only 38 out of the 53 SNPs were evaluated given that 14 were shown to be monomorphic in the Mexican population (Suppl.

Table 2 Atherogenic profile of study subjects

\begin{tabular}{|c|c|c|c|c|c|}
\hline & $\begin{array}{l}\text { Normal Triglycerides } \\
n=73\end{array}$ & $\begin{array}{l}\text { CHTG } \\
n=85\end{array}$ & $\begin{array}{l}\text { FHTG } \\
n=84\end{array}$ & $\begin{array}{l}P \text { value } \\
\text { all }\end{array}$ & $\begin{array}{l}\text { P value* } \\
\text { FHTG vs CHTG }\end{array}$ \\
\hline Age (years) & $49[45-54]$ & 50 [37-55] & $43[37-47]^{b}$ & 0.002 & 0.001 \\
\hline $\mathrm{BMI}\left(\mathrm{kg} / \mathrm{m}^{2}\right)$ & $26.4[24.2-28.7]^{a}$ & 28.7 [25.9-31.1] & $28.9[26.1-32.1]$ & 0.008 & 0.813 \\
\hline Waist (cm) & $90[84-98]^{\mathrm{a}}$ & 94 [88-104] & 96 [88-100] & 0.004 & 0.800 \\
\hline Leptin $(\mu g / L)$ & $5.6[2.3-13.6]$ & $8.7[7.2-28]$ & $5.7[2.6-8.7]$ & $<0.001$ & $<0.001$ \\
\hline Adiponectin $(\mu \mathrm{g} / \mathrm{L})$ & $11.4[8.8-14.6]^{\mathrm{a}}$ & $6.8[4.3-10.4]$ & $5.9[4.5-8.4]$ & $<0.001$ & 0.146 \\
\hline Apo B (mg/dL) & $103[86-114]$ & 110 [109-117] & 91.8 [82-97.6] & $<0.001$ & $<0.001$ \\
\hline Apo A-II (mg/dL) & 1894 [996-2858] & 426.5 [401.4-456.5] & 702 [497-1062] & $<0.001$ & $<0.001$ \\
\hline Apo C-III (mg/dL) & $10.7[7.3-13.4]$ & 30.68 [24.5-38] & 22.8 [13.6-37] & $<0.001$ & 0.231 \\
\hline ANGPTL3 (ng/mL) & $9[6.6-11.2]$ & 18.8 [13.6-22] & 108 [10.8-372] & $<0.001$ & $<0.001$ \\
\hline ANGPTL4 (ng/mL) & $50.5[21.5-145.9]$ & 180.9 [151.9-225.3] & 384 [239-483] & $<0.001$ & $<0.001$ \\
\hline FGF-19 (pg/mL) & 15 [10-81] & 15 [7-18] & $77[10-156]^{b}$ & 0.052 & 0.071 \\
\hline FGF-21 (pg/mL) & $55.5[32-89]$ & $12.5[2-22]$ & $168[66-316]$ & $<0.001$ & $<0.001$ \\
\hline FGF-23 (pg/mL) & 25 [18-38] & $17.5[16-22]$ & $33[22-50]$ & 0.127 & 0.417 \\
\hline FABP1 (ng/mL) & $37[2.15-302.1]^{\mathrm{a}}$ & 15.5 [13.6-20.8] & $13[1-45]$ & 0.010 & 0.056 \\
\hline
\end{tabular}

Median [25th percentile-75th percentile] or percentages are shown

Kruskall Wallis test for metabolic traits adjusted for age, BMI, triglycerides levels and sex;

${ }^{a}$ post hoc $P<0.01$ by Dunn test: Normal triglycerides subjects different among the other groups

${ }^{b}$ post hoc $P<0.01$ by Dunn test: FHTG subjects different only from CHTG subjects

c post hoc $P<0.01$ by Dunn test: CHTG subjects different among the other groups

*U Mann-Whitney test 
Table 3 Performance of individual and combined factors in predicting FHTG compared to CHTG using logistic regression analyses. *Model adjusted for age

\begin{tabular}{|c|c|c|c|c|c|c|c|}
\hline Variable & $\begin{array}{l}\text { AUC } \\
(95 \% \mathrm{Cl})\end{array}$ & $\begin{array}{l}\text { Cut-off } \\
\text { value }\end{array}$ & BIC & $\begin{array}{l}\text { Sensitivity } \\
(95 \% \mathrm{Cl})\end{array}$ & $\begin{array}{l}\text { Specificity } \\
(95 \% \mathrm{Cl})\end{array}$ & $\begin{array}{l}\text { PPV } \\
(95 \% \mathrm{Cl})\end{array}$ & $\begin{array}{l}\text { NPV } \\
(95 \% \mathrm{Cl})\end{array}$ \\
\hline Age (years) & $\begin{array}{l}0.633 \\
(0.539- \\
0.727)\end{array}$ & $<45.0$ & 217.80 & $\begin{array}{l}72.6(61.8- \\
81.8)\end{array}$ & $\begin{array}{l}67.0(56.0- \\
76.9)\end{array}$ & $\begin{array}{l}68.8 \\
(58.0- \\
78.1)^{f}\end{array}$ & $\begin{array}{l}66.3 \\
(55.4- \\
76.2)\end{array}$ \\
\hline Apo B (mg/dL) & $\begin{array}{l}0.853(0.787- \\
0.918)\end{array}$ & $<102.0$ & 145.29 & $\begin{array}{l}92.8(85.1- \\
97.3)\end{array}$ & $\begin{array}{l}73.3(61.8- \\
82.9)\end{array}$ & $\begin{array}{l}81.8 \\
(68.5- \\
87.4)\end{array}$ & $\begin{array}{l}57.6 \\
(46.4- \\
76.5)\end{array}$ \\
\hline Apo A-II (mg/dL) & $\begin{array}{l}0.878(0.824- \\
0.932)\end{array}$ & $>0.472$ & 143.22 & $\begin{array}{l}85.7(76.4- \\
92.4)\end{array}$ & $\begin{array}{l}78.8(68.6- \\
86.9)\end{array}$ & $\begin{array}{l}77.0 \\
(65.2- \\
83.8)\end{array}$ & $\begin{array}{l}60.9 \\
(50.3- \\
74.9)\end{array}$ \\
\hline ANGPTL3 (ng/mL) & $\begin{array}{l}0.530(0.433- \\
0.628)\end{array}$ & $>214.7$ & 199.56 & $\begin{array}{l}48.8(37.7- \\
60.0)\end{array}$ & $\begin{array}{l}91.5(82.5- \\
96.8)\end{array}$ & $\begin{array}{l}87.2 \\
(74.8- \\
91.5)\end{array}$ & $\begin{array}{l}60.2 \\
(49.0- \\
81.0)\end{array}$ \\
\hline $\mathrm{FGF}-21(\mathrm{pg} / \mathrm{mL})$ & $\begin{array}{l}0.804(0.737- \\
0.872)\end{array}$ & $>27.0$ & 204.70 & $\begin{array}{l}96.4(89.9- \\
99.2)\end{array}$ & $\begin{array}{l}57.6(46.4- \\
68.3)\end{array}$ & $\begin{array}{l}60.0 \\
(28.7- \\
81.9)\end{array}$ & $\begin{array}{l}47.9 \\
(15.7- \\
88.5)\end{array}$ \\
\hline Sex + Apo B $<102 \mathrm{mg} / \mathrm{dL}$ & $\begin{array}{l}0.858 \\
(0.799- \\
0.917)\end{array}$ & $>0.66$ & 149.91 & $\begin{array}{l}90.5(82.1 \\
98.9)\end{array}$ & $\begin{array}{l}73.2(61.4- \\
85.0)\end{array}$ & $\begin{array}{l}80.0 \\
(69.9- \\
90.1)\end{array}$ & $\begin{array}{l}86.7(75.8 \\
97.6)\end{array}$ \\
\hline Apo B<102 mg/dL + apo A-\|l $>0.472$ mg/dL & $\begin{array}{l}0.917 \\
(0.874- \\
0.960)\end{array}$ & $>0.94$ & 114.62 & $\begin{array}{l}76.2(65.6- \\
84.8)\end{array}$ & $\begin{array}{l}92.9(84.3- \\
97.7)\end{array}$ & $\begin{array}{l}92.7 \\
(83.9- \\
95.7)\end{array}$ & $\begin{array}{l}76.7 \\
(66.3- \\
91.3)\end{array}$ \\
\hline Apo B $<102 \mathrm{mg} / \mathrm{dL}+$ apo A-II $>0.472 \mathrm{mg} / \mathrm{dL}+$ Sex & $\begin{array}{l}0.934 \\
(0.894- \\
0.975)\end{array}$ & $>0.49$ & 113.6 & $\begin{array}{l}95.2(88.2- \\
98.7)\end{array}$ & $\begin{array}{l}78.9(67.6- \\
87.7)\end{array}$ & $\begin{array}{l}84.2(74.8- \\
95.2)\end{array}$ & $\begin{array}{l}93.3 \\
(84.0- \\
96.4)\end{array}$ \\
\hline Apo B $<102 \mathrm{mg} / \mathrm{dL}+$ apo A-\|l $>0.472 \mathrm{mg} / \mathrm{dL}+\mathrm{Sex}^{*}$ & $\begin{array}{l}0.944 \\
(0.908- \\
0.981)\end{array}$ & $>0.64$ & 114.09 & $\begin{array}{l}89.3(80.6- \\
95.0)\end{array}$ & $\begin{array}{l}85.9(75.6- \\
93.0)\end{array}$ & $\begin{array}{l}88.2 \\
(79.2- \\
94.4)\end{array}$ & $\begin{array}{l}87.1 \\
(77.2- \\
93.7)\end{array}$ \\
\hline $\begin{array}{l}\text { Apo B }<102 \mathrm{mg} / \mathrm{dL}+\text { apo All }>0.472 \mathrm{mg} / \mathrm{dL}+\text { Sex }+ \text { FGF-21 }> \\
27 \mathrm{pg} / \mathrm{mL} \text {, ANGPTL3 }>214 \mathrm{ng} / \mathrm{mL}^{*}\end{array}$ & $\begin{array}{l}0.969 \\
(0.920- \\
0.999)\end{array}$ & $>0.45$ & 107.88 & $\begin{array}{l}98.9(94.5- \\
99.9)\end{array}$ & $92.5(78-92)$ & $\begin{array}{l}89.3 \\
(80.7- \\
99.7)\end{array}$ & $\begin{array}{l}98.7 \\
(92.3- \\
99.2)\end{array}$ \\
\hline
\end{tabular}

PPV Positive predictive value; NPV Negative predictive value; AUC Area under curve; BIC Bayesian information Crite

Table 1). Only eight variants reached statistical significance for an association with FHTG (Suppl. Table 2): APOA5/BUD13 (rs964184, $\left.P=2.54 \times 10^{-07}\right), \quad$ LIPC (rs1532085, $P=0.0055)$, INSR (rs7248104, $P=0.0071$ ), GCKR (rs1260326, $P$ = 0.0155), LRPAP1 (rs6831256, $P=$ 0.0247), PLTP (rs6065906, $P=0.0304), \quad C Y P 26 A 1$ (rs2068888, $P=0.0366$ ) and $M L X I P L$ (rs2286276, $P=$ 0.0375) (Suppl. Table 2). In contrast, seven variants were associated with CHTG: $A P O A 5 / B U D 13$ (rs964184, $P=$ $\left.7.7 \times 10^{-12}\right), \quad$ GCKR $(\mathrm{rs} 1260326, \quad P=0.0046), \quad$ LRP 1 (rs11613352, $P=0.0069)$, JMJD1C (rs10761731, $P=$ 0.0177), CILP2 (rs10401969, $P=0.0246), \quad C T F 1$ (rs11649653, $P=0.0457)$ and $L P L$ (rs12678919, $P=$ 0.0577) (Suppl. Table 2). However, when a genetic risk score was developed using the complete set of 38 known TG associated variants, it explained only $1.78 \%$ [0.4544.47] of the variance in TG levels in the FHTG sample, and $6.73 \%$ [0.47-9.56] of the variance in TG levels in the CHTG sample (Table 4). A similar pattern of allele frequencies was seen between CHTG and FHTG groups, except for, except for APOA5/BUD13 rs964184, which showed higher frequency in FHTG compared to CHTG (Suppl. Figure 1).

Role of the rare monogenic TG component with FHTG Regarding the monogenic component set, 37 genetic variants previously reported as associated with FCS and FHTG were analyzed (Suppl. Table 3). Only 5 of the 37 variants were present in the FHTG patients ( $L P L$, p.Val227Ala, GPIHBP1 rs72691625, LMF1 rs4984948, LMF1 rs35168378 and LMF1 rs143076454). However, except for $L P L$, p. Val227Ala, the other 4 variants were

Table 4 The explained variance in TG levels using a polygenic risk score in FHTG and CHTG

\begin{tabular}{lll}
\hline Group & $\begin{array}{l}\text { Explained variance (\%) } \\
\text { [IC 0.025-0.975] }\end{array}$ & $P$ \\
\hline FHTG & $1.78[0.45-4.47]$ & $<2.2 \times 10^{-16}$ \\
CHTG & $6.73[0.47-9.56]$ &
\end{tabular}

IC from bootstrapped R-squared of models performing linear regression of TG levels on polygenic scores. The polygenic risk score was computed using the complete set of 38 known TG associated variants. $P$ value of the comparison between the variance explained in FHTG versus CHTG 
also present in the normoglycemic and CHTG subgroups, suggesting that they do not drive the FHTG phenotype. Furthermore, 2 additional variants were found in the normoglycemic subgroup but not in the FHTG subgroup (Suppl. Table 4). Finally, the same pattern of allele frequencies was seen between CHTG and FHTG groups (Suppl. Figure 1).

\section{Discussion}

This study demonstrates that FHTG has clinical and biochemical characteristics that distinguish it from other forms of common mild-to-moderate hypertriglyceridemia (CHTG). After controlling for confounding variables, FHTG cases have lower HOMAB\%, HDL-C, apo B, and leptin levels and higher FGF-21, ANGPTL3 and ANGPTL4 levels than CHTG subjects. Only apo B, FGF-21, ANGPLT3 and apo A-II concentrations, along with gender, age and BMI were independent components of a model to detect FHTG compared with CHTG and normotriglyceridemic controls (AUC 0.948, 95\%CI 0.901-0.970, 98.5\% sensitivity, $92.2 \%$ specificity, $P<0.001)$.

The main pathophysiological mechanism of hypertriglyceridemia in FHTG is abnormal VLDL composition without alteration in VLDL particle number [21]. As a result, plasma apo B levels in FHTG subjects are normal or low. High TG levels in FHTG subjects are not determined by hepatic VLDL-apo B overproduction, it is likely to be a result of decreased TG clearance (Fig. 1) [21].

FGF-21 and ANGPTL3, mRNA and protein levels are regulated by the carbohydrate response element-binding protein (ChREBP) [46, 47]. Therefore, ChREBP, a transcriptional activator of glycolytic and lipogenic genes may play a role in the development of hypertriglyceridemia in FHTG by regulating the secretion of those molecules (Fig. 1) altering the VLDL-particle composition without changing their numbers. Interestingly, there was a stronger association of ChREBP gene with FHTG than with CHTG $(P=0.037$ and 0.092 , respectively, Suppl. Table 2$)$.

In humans, serum FGF-21 correlates with de novo lipogenic rates measured by stable isotopic tracers [31], contributing to increased hepatic triglycerides synthesis. Lee $\mathrm{Y}$ et al. showed that FGF-21 concentrations positively correlate with TG, insulin and HOMA-IR - [48, 49], and Akyildiz Zl et al. showed that TG might play an important role in predicting FGF21 concentrations [50]. Endoplasmic reticulum (ER) stress is another factor that may increase FGF21 concentrations, it is well known that FHTG subjects have high postprandial lipemia that may lead to atherosclerosis and endothelial dysfunction with ER stress [51]. Insulin resistance and the affluence of fatty acids towards the liver contributes to the inflammatory process seen in FHTG.

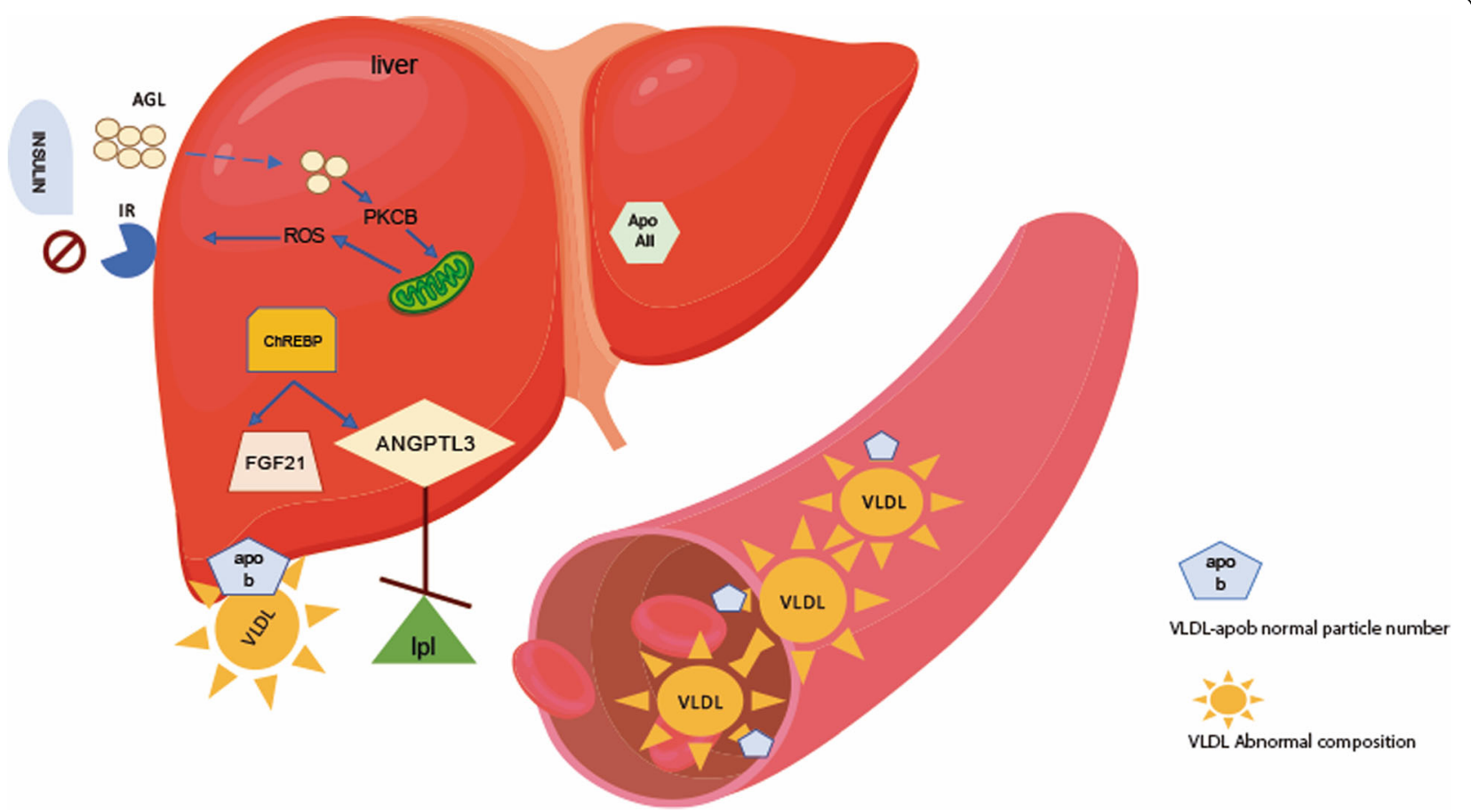

Fig. 1 Proposed physiopathological mechanisms that may contributed to the genesis of familial hypertriglyceridemia. Inhibition of LPL orchestrated by FGF21 and ANGPTL3, both of which are regulated by CHREBP. This results in alterations in the composition of VLDL particles with numbers remaining unchanged 
Furthermore, the higher concentration of angiopoietin-like 3 may cause decreased triglycerides clearance [52]. ANGPTL-3 is a major inhibitor of lipoprotein lipase (LPL) activity, the principal triglycerides hydrolyzing protein $[53,54]$. Recent evidence has confirmed the prominent role that inhibitors of ANGPTL3 have in the removal of triglycerides-rich particles, LDL$\mathrm{C}$ and apo $\mathrm{B}$ levels, probably due to an increased clearance of apo B containing lipoproteins and their remnants [33]. Monoclonal antibodies and antisense oligonucleotides that target ANGPTL3, and 4 are potentially an efficient therapeutic strategy for cardiovascular risk reduction in hypertriglyceridemia, especially in patients with FHTG $[55,56]$. The results suggest that this molecule may be involved in the pathogenesis of FHTG and its measurement may be helpful for diagnosis (Fig. 1). A recent publication by Chen YQ et al. showed how during feeding, ANGPTL8 forms a circulating complex with ANGPTL3 that increases its ability to inhibit LPL, thus minimizing FA uptake into skeletal muscle [57].

Therefore, a model using a combination of apo B, FGF-21, ANGPTL3 and apo A-II levels is proposed in order to improve identification of FHTG subjects from the wide constellation of hypertriglyceridemic phenotypes (Figs. 1 and 2) This model showed an excellent performance in this cohort of patients.
Regarding the genetic components, 8 out of 44 common variants were found to be associated with FHTG, and only two were also associated with CHTG (APOA5/ $B U D 13$, rs964184 and GCKR, rs1260326). The set of variants associated with FHTG but not with CHTG included LIPC, rs1532085, INSR, rs7248104, LRPAP1, rs6831256, PLTP, rs6065906 CYP26A1, rs2068888 and MLXIPL, rs2286276.

Notably, none of the main 5 genes associated with FCS explained the FHTG phenotype in these patients. Despite the fact that some of the FHTG patients were carriers of previously reported variants, they were also present in the normoglycemic subgroup. Only $\mathrm{p}$. Val227Ala within the LPL gene was present in FHTG but not in normotriglyceridemic participants.

A primary cause of FCS is the recessive inheritance of rare variants in certain genes and that FHTG patients may be compound heterozygotes (i.e. heterozygous carriers of more than 1 rare variant): none of the FHTG patients were homozygous for any of the studied rare variants. Furthermore, compound heterozygote (rs35168378 + rs143076454) patients were identified in both normotriglyceridemic and FHTG patients.

The results show that neither the previously known set of common variants, nor a set of monogenic variants, explain a significant proportion of the genetic

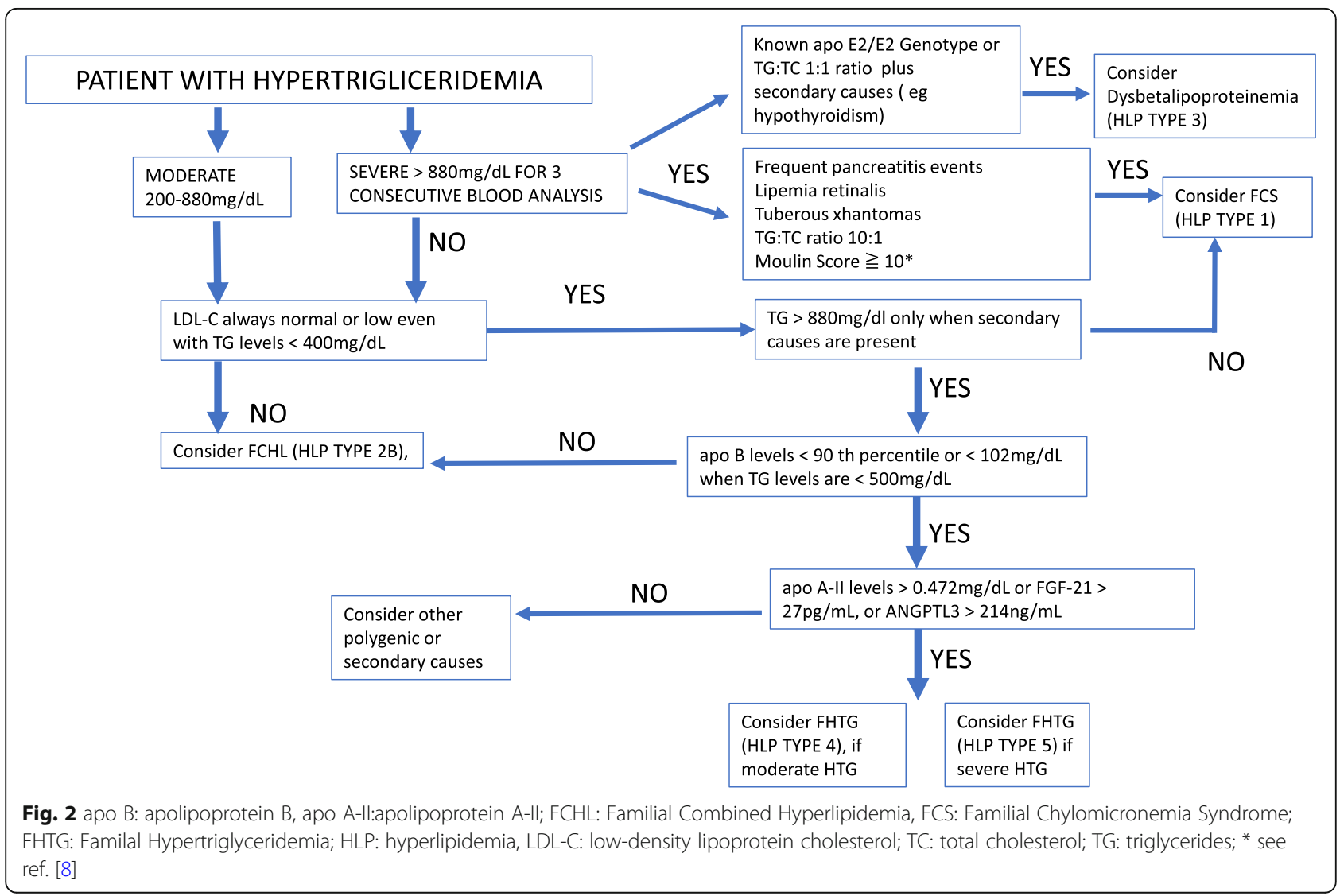


contribution to FHTG in Mexican subjects. Over the past years, many GWAS of dyslipidemias have been performed, but only a small percentage of the total variance in phenotypes has been explained by the genetic component. Thus, even though the current results are insufficient to accurately assess the likelihood of developing hypertriglyceridemia, the findings may be helpful in directing studies towards new disease mechanisms and targets for prevention and therapy. This highlights the need for the identification of additional genetic components of FHTG through free-hypothesis approaches. Previously, we have reported that the Mexican population has genetic variants which are unique to this and other Native American-derived populations. Such variants have higher effect sizes, explain a greater percentage of the variance and its corresponding genes and pathways may represent new potential therapeutic targets [58-60]. The results highlight the need for a more extensive genetic characterization of FHTG through whole exome/ genome sequencing to identify additional ethnic-specific gene variants.

\section{Study strengths and limitations}

This is the first attempt for the complete description and characterization (clinical, biochemical, genetic) of the FHTG phenotype, which is frequently confused with other HTG phenotypes.

We propose a whole genome sequencing approach given that the Mexican population shows genetic variation that occurs at a very low frequency or that is absent among other populations. Moreover, such variation may have a higher effect size compared to other populations. Although most evidence has been provided for the genetics of type 2 diabetes the same may presumably happen with other metabolic diseases, such as hypertriglyceridemia [58, 59]. Finally, we recognize as a limitation of the study, the lack of information on the contribution of heterozygous forms of causal variants of FCS, although there were a few individuals who were heterozygous carriers of FCS mutations. In addition, the number of subjects included in the analysis of pro-atherogenic profile and endocrine regulatory proteins was small. Furthermore, it is necessary to authenticate these findings in other populations and with a greater number of individuals, to improve the external validity of the results. A family study for all the probands in the CHTG group was not available so we cannot definitively confirm that these individuals belonged to the FCHL phenotype, but the lipid profile is characteristic of this disease, especially when FCHL patient have a hypertriglyceridemia phenotype plus a secondary cause [17].

\section{Conclusions}

We propose that FHTG is a unique entity having a distinct clinical, biochemical and genetic profile that distinguishes it from other forms of HTG (Fig. 2). It is characterized by higher concentrations of insulin, FGF21, ANGPTL3, apo A-II and lower levels of apo B. Furthermore, neither the previously known set of common variants, nor a set of monogenic variants, explain a significant proportion of the genetic contribution to FHTG in Mexican subjects. This study is an important step in the study of hypertriglyceridemia confirming the presence of subtle biochemical and genetic differences associated with different HTG phenotypes.

\section{Supplementary Information}

The online version contains supplementary material available at https://doi. org/10.1186/s12944-021-01436-6.

Additional file 1.

Additional file 2 .

\begin{abstract}
Abbreviations
ANGPTLs: Angiopoietin-like proteins; Apo All: Apolipoprotein A-Il; Apo

B: Apolipoprotein B; BIC: Bayesian Information Criterion; BMI: Body mass index; CHTG: Common mild-to-moderate hypertriglyceridemia; FABP1/L-FABP

: Liver-type fatty acid-binding protein; FCHL: Familial combined

hyperlipidemia; FCS: Familial chylomicronemia syndrome; FGFs: Fibroblast growth factor proteins; FHTG: Familial hypertriglyceridemia;

GPIHBP1: Glycosylphosphatidylinositol-anchored high-density lipoproteinbinding protein 1; GRS: Genetic risk score; GWAS: Genome-wide association studies; HDL-C: High-density lipoprotein cholesterol; HLP: Hyperlipidemia; HTG: Hypertriglyceridemia; LDL-C: Low-density lipoprotein cholesterol; LMF1: Lipase maturation factor 1; LPL: Lipoprotein lipase; NAFLD: Nonalcoholic fatty liver disease; ROC: Receiver operating characteristic; SNPs: Single nucleotide polymorphisms; SVM: Upport vector machines; TG: Triglycerides; T2D: Type 2 diabetes; VLDL: Very low-density lipoprotein cholesterol
\end{abstract}

\section{Acknowledgements}

We thank the technical and laboratory personnel at the Endocrinology and Metabolism Department for their logistic support, as well as Angelina LopezEstrada' Maribel Rodríguez-Torres, Carmen Moreno-Villatoro, Adriana CruzLópez and Saul Cano-Colín for their technical support. We want to express our gratitude to the patients enrolled in this study.

Ivette Cruz-Bautista thanks the PhD program on Medical Sciences (Programa de Maestria y Doctorado en Ciencias Medicas, Odontologicas y de la Salud PMDCMOS) supported by the Univesidad Nacional Autonoma de Mexico (UNAM) and CONACYT with CVU number 169342.

\section{Authors' contributions}

CAAS and TTL conceived the study. LGM, XChR, XRF, AAC, BBB, DEL, DGV $F R O, C L C h$, AJM recruited the sample and performed all the clinical descriptions. ICB, AHC, OYBC, and HMM analyzed the data. MOS, RRG and YSK performed the experiments. MGL, LGP performed the measurements. $I C B$, AHC wrote the manuscript and CAA, TTL reviewed the manuscript. RM reviewed the correct version in proper English. The author(s) read and approved the final manuscript.

\section{Funding}

This study was sponsored by funds from the Endocrinology and Metabolism Department at the INCMNSZ and funds from the Fondo Sectorial CONACYT (DIA 11-156770). This project also received support from Fondo Sectorial DIA 57411 /14-1 SALUD -2011-1-161570 and PAPIIT/DGAPA IN215219. 


\section{Availability of data and materials}

The datasets used and/or analysed during the current study are available from the corresponding author on reasonable request.

\section{Ethics approval and consent to participate}

All subjects signed informed consent on entering the study. The study protocol conformed to the ethical guidelines of the 1975 Declaration of Helsinki and was approved by the Research and Ethics Committee of the hospital. Ref. 574.

\section{Consent for publication}

Not applicable.

\section{Competing interests}

Authors declare no conflicts of interest.

\section{Author details}

'Unidad de Investigación de Enfermedades Metabólicas, Instituto Nacional de Ciencias Médicas y Nutrición Salvador Zubirán, Vasco de Quiroga 15, Tlalpan, 14080 Mexico City, Mexico. ${ }^{2}$ Departamento de Endocrinología y Metabolismo, Instituto Nacional de Ciencias Médicas y Nutrición Salvador Zubirán, Vasco de Quiroga 15, Tlalpan, 14080 Mexico City, Mexico. ${ }^{3}$ Unidad de Biología Molecular y Medicina Genómica, Instituto Nacional de Ciencias Médicas y Nutrición Salvador Zubirán e Instituto de Investigaciones Biomédicas de la UNAM, Mexico City, Mexico. ${ }^{4}$ CONACyT. Instituto Nacional de Ciencias Médicas y Nutrición Salvador Zubirán, Mexico City, Mexico. ${ }^{5}$ Departamento de Economía, Universidad Autónoma Metropolitana, Mexico City, Mexico. ${ }^{6}$ Tecnológico de Monterrey, Escuela de Medicina y Ciencias de la Salud, Ave. Morones Prieto 3000, 64710 Monterrey, NL, Mexico. 'Research Division, Instituto Nacional de Geriatría, Mexico City, Mexico. ${ }^{8}$ Departamento de Oncología Médica, Instituto Nacional de Cancerología, Mexico City, Mexico. ${ }^{9}$ Departamento de Biotecnología Agrícola, Instituto Politécnico Nacional, Mexico City, Mexico.

\section{Received: 26 October 2020 Accepted: 26 January 2021} Published online: 15 February 2021

\section{References}

1. Laufs U, Parhofer KG, Ginsberg HN, Hegele RA. Clinical review on triglycerides. Eur Heart J. 2019;41(1):99-109C.

2. Catapano AL, Graham I, De Backer G, Wiklund O, Chapman MJ, Drexel H, et al. 2016 ESC/EAS guidelines for the Management of Dyslipidaemias. Eur Heart J. 2016;37(39):2999-3058 PubMed PMID: 27567407. Epub 2016/08/28. eng.

3. Mach F, Baigent C, Catapano AL, Koskinas KC, Casula M, Badimon L, et al. 2019 ESC/EAS guidelines for the management of dyslipidaemias: lipid modification to reduce cardiovascular risk. Eur Heart J. 2020;41(1):111-88 PubMed PMID: 31504418. Epub 2019/09/11. eng.

4. Aguilar-Salinas CA, Gómez-Pérez FJ, Rull J, Villalpando S, Barquera S, Rojas R. Prevalence of dyslipidemias in the Mexican National Health and nutrition survey 2006. Salud publica de Mexico. 2010;52(Suppl. 1):S44-53 PubMed PMID: 20585729. Epub 2010/07/24. eng.

5. Aguilar-Salinas CA, Tusie-Luna T, Pajukanta P. Genetic and environmental determinants of the susceptibility of Amerindian derived populations for having hypertriglyceridemia. Metab Clin Exp. 2014;63(7):887-94 PubMed PMID: 24768220. Pubmed Central PMCID: PMC4315146. Epub 2014/04/29. eng.

6. Ko A, Cantor RM, Weissglas-Volkov D, Nikkola E, Reddy PM, Sinsheimer JS, et al. Amerindian-specific regions under positive selection harbour new lipid variants in Latinos. Nat Commun. 2014;5:3983 PubMed PMID: 24886709. Pubmed Central PMCID: PMC4062071. Epub 2014/06/03. eng.

7. Austin MA, Edwards KL, Monks SA, Koprowicz KM, Brunzell JD, Motulsky AG, et al. Genome-wide scan for quantitative trait loci influencing LDL size and plasma triglyceride in familial hypertriglyceridemia. J Lipid Res. 2003;44(11): 2161-8 PubMed PMID: 12923221. Epub 2003/08/19. eng.

8. Moulin P, Dufour R, Averna M, Arca M, Cefalù AB, Noto D, et al. Identification and diagnosis of patients with familial chylomicronaemia syndrome (FCS): expert panel recommendations and proposal of an "FCS score". Atherosclerosis. 2018;275:265-72 PubMed PMID: 29980054. Epub 2018/07/07. eng.
9. Davidson M, Stevenson M, Hsieh A, Ahmad Z, Roeters van Lennep J, Crowson $\mathrm{C}$, et al. The burden of familial chylomicronemia syndrome: results from the global IN-FOCUS study. J Clin Lipidol. 2018;12(4):898-907 e2 PubMed PMID: 29784572. Epub 2018/05/23. eng.

10. Surendran RP, Visser ME, Heemelaar S, Wang J, Peter J, Defesche JC, et al. Mutations in LPL, APOC2, APOA5, GPIHBP1 and LMF1 in patients with severe hypertriglyceridaemia. J Intern Med. 2012;272(2):185-96 PubMed PMID: 22239554. Pubmed Central PMCID: PMC3940136. Epub 2012/01/14. eng.

11. D'Erasmo L, Di Costanzo A, Cassandra F, Minicocci I, Polito L, Montali A, et al. Spectrum of mutations and long-term clinical outcomes in genetic Chylomicronemia syndromes. Arterioscler Thromb Vasc Biol. 2019;39(12): 2531-41 PubMed PMID: 31619059. Epub 2019/10/18. eng.

12. Serveaux Dancer M, Di Filippo M, Marmontel O, Valéro R, Piombo Rivarola MDC, Peretti N, et al. New rare genetic variants of LMF1 gene identified in severe hypertriglyceridemia. J Clin Lipidol. 2018;12(5):1244-52 PubMed PMID: 30037590. Epub 2018/07/25. eng.

13. Cefalù $A B$, Spina $R$, Noto $D$, Ingrassia $V$, Valenti $V$, Giammanco $A$, et al. Identification of a novel LMF1 nonsense mutation responsible for severe hypertriglyceridemia by targeted next-generation sequencing. J Clin Lipidol. 2017;11(1):272-81 e8 PubMed PMID: 28391895. Epub 2017/04/11. eng.

14. Wang J, Hegele RA. Homozygous missense mutation (G56R) in glycosylphosphatidylinositol-anchored high-density lipoprotein-binding protein 1 (GPI-HBP1) in two siblings with fasting chylomicronemia (MIM 144650). Lipids Health Dis. 2007;6:23 PubMed PMID: 17883852. Pubmed Central PMCID: PMC2039732. Epub 2007/09/22. eng.

15. Dron JS, Wang J, Mclntyre AD, Cao H, Hegele RA. The polygenic nature of mild-to-moderate hypertriglyceridemia. J Clin Lipidol. 2020;14(1):28-34 e2 PubMed PMID: 32033914. Epub 2020/02/09. eng.

16. O'Dea LSL, MacDougall J, Alexander VJ, Digenio A, Hubbard B, Arca M, et al. Differentiating familial Chylomicronemia syndrome from multifactorial severe hypertriglyceridemia by clinical profiles. J Endocrine Soc. 2019;3(12): 2397-410 PubMed PMID: 31777768. Pubmed Central PMCID: PMC6864364. Epub 2019/11/30. eng.

17. Bello-Chavolla OY, Kuri-García A, Ríos-Ríos M, Vargas-Vázquez A, CortésArroyo JE, Tapia-González G, et al. FAMILIAL COMBINED HYPERLIPIDEMIA: CURRENT KNOWLEDGE, PERSPECTIVES, AND CONTROVERSIES. Revista de investigacion clinica; organo del Hospital de Enfermedades de la Nutricion. 2018;70(5):224-36 PubMed PMID: 30307446. Epub 2018/10/12. eng.

18. Glueck CJ, Tsang R, Fallat R, Buncher CR, Evans G, Steiner P. Familial hypertriglyceridemia: studies in 130 children and 45 siblings of 36 index cases. Metab Clin Exp. 1973;22(10):1287-309 PubMed PMID: 4784529. Epub 1973/10/01. eng.

19. Weissglas-Volkov D, Aguilar-Salinas CA, Nikkola E, Deere KA, Cruz-Bautista I, Arellano-Campos O, et al. Genomic study in Mexicans identifies a new locus for triglycerides and refines European lipid loci. J Med Genet. 2013;50(5): 298-308 PubMed PMID: 23505323. Pubmed Central PMCID: PMC3917605. Epub 2013/03/19. eng.

20. Dron JS, Wang J, Cao H, McIntyre AD, lacocca MA, Menard JR, et al. Severe hypertriglyceridemia is primarily polygenic. J Clin Lipidol. 2019;13(1):80-8 PubMed PMID: 30466821. Epub 2018/11/24. eng.

21. Brunzell JD. Clinical practice. Hypertriglyceridemia. N Engl J Med. 2007; 357(10):1009-17 PubMed PMID: 17804845. Epub 2007/09/07. eng.

22. Lewis GF, Xiao C, Hegele RA. Hypertriglyceridemia in the genomic era: a new paradigm. Endocr Rev. 2015;36(1):131-47 PubMed PMID: 25554923. Epub 2015/01/03. eng.

23. Bouabdellah M, Iraqi H, Benlian P, Berqia I, Benchekroun L, Chraïbi A, et al. Familial hypertriglyceridemia: biochemical, clinical and molecular study in a Moroccan family. Annales de biologie clinique. 2015;73(4):474-84 PubMed PMID: 26104879. Epub 2015/06/25. Hypertriglycéridémie familiale : étude biochimique, clinique et moléculaire dans une famille marocaine. fre.

24. Albrink MJ, Man EB. Serum triglycerides in coronary artery disease. AMA Archiv Int Med. 1959;103(1):4-8 PubMed PMID: 13605296. Epub 1959/01/01. eng.

25. Austin MA, McKnight B, Edwards KL, Bradley CM, McNeely MJ, Psaty BM, et al. Cardiovascular disease mortality in familial forms of hypertriglyceridemia: a 20-year prospective study. Circulation. 2000;101(24): 2777-82 PubMed PMID: 10859281. Epub 2000/06/22. eng.

26. Nordestgaard BG, Varbo A. Triglycerides and cardiovascular disease. Lancet (London, England). 2014;384(9943):626-35 PubMed PMID: 25131982. Epub 2014/08/19. eng. 
27. Stefanutti C, Labbadia G, Morozzi C. Severe hypertriglyceridemia-related acute pancreatitis: myth or reality? Ther Apheresis Dialysis. 2013;17(4):464-5 PubMed PMID: 23931892. Epub 2013/08/13. eng.

28. Hegele RA, Ginsberg HN, Chapman MJ, Nordestgaard BG, Kuivenhoven JA, Averna $\mathrm{M}$, et al. The polygenic nature of hypertriglyceridaemia: implications for definition, diagnosis, and management. Lancet Diabetes Endocrinol. 2014;2(8):655-66 PubMed PMID: 24731657. Pubmed Central PMCID: PMC4201123. Epub 2014/04/16. eng.

29. Hopkins PN, Heiss G, Ellison RC, Province MA, Pankow JS, Eckfeldt JH, et al. Coronary artery disease risk in familial combined hyperlipidemia and familial hypertriglyceridemia: a case-control comparison from the National Heart, Lung, and Blood Institute family heart study. Circulation. 2003;108(5):519-23 PubMed PMID: 12847072. Epub 2003/07/09. eng.

30. Mirza MA, Alsiö J, Hammarstedt A, Erben RG, Michaëlsson K, Tivesten A, et al. Circulating fibroblast growth factor-23 is associated with fat mass and dyslipidemia in two independent cohorts of elderly individuals. Arterioscler Thromb Vasc Biol. 2011;31(1):219-27 PubMed PMID: 20966399. Epub 2010/ 10/23. eng.

31. Novotny D, Vaverkova H, Karasek D, Lukes J, Slavik L, Malina P, et al. Evaluation of total adiponectin, adipocyte fatty acid binding protein and fibroblast growth factor 21 levels in individuals with metabolic syndrome. Physiol Res. 2014;63(2):219-28 PubMed PMID: 24397811. Epub 2014/01/09. eng.

32. Wu X, Ge H, Baribault H, Gupte J, Weiszmann J, Lemon B, et al. Dual actions of fibroblast growth factor 19 on lipid metabolism. J Lipid Res. 2013;54(2): 325-32 PubMed PMID: 23204296. Pubmed Central PMCID: PMC3588862. Epub 2012/12/04. eng

33. Ruscica M, Zimetti F, Adorni MP, Sirtori CR, Lupo MG, Ferri $N$. Pharmacological aspects of ANGPTL3 and ANGPTL4 inhibitors: new therapeutic approaches for the treatment of atherogenic dyslipidemia. Pharmacol Res. 2020;153:104653 PubMed PMID: 31931117. Epub 2020/01/ 14. eng.

34. Wang YT, Liu CH, Zhu HL. Fatty acid binding protein (FABP) inhibitors: a patent review (2012-2015). Expert Opin Ther Patents. 2016;26(7):767-76 PubMed PMID: 27109571. Epub 2016/04/26. eng.

35. Castellani LW, Nguyen CN, Charugundla S, Weinstein MM, Doan CX, Blaner WS, et al. Apolipoprotein All is a regulator of very low density lipoprotein metabolism and insulin resistance. J Biol Chem. 2008;283(17):11633-44 PubMed PMID: 18160395. Pubmed Central PMCID: PMC2431075. Epub 2007/12/28. eng

36. Martin SS, Blaha MJ, Elshazly MB, Toth PP, Kwiterovich PO, Blumenthal RS, et al. Comparison of a novel method vs the Friedewald equation for estimating low-density lipoprotein cholesterol levels from the standard lipid profile. Jama. 2013;310(19):2061-8 PubMed PMID: 24240933. Pubmed Central PMCID: PMC4226221. Epub 2013/11/19. eng.

37. Sampson M, Ling C, Sun Q, Harb R, Ashmaig M, Warnick R, et al. A new equation for calculation of low-density lipoprotein cholesterol in patients with Normolipidemia and/or hypertriglyceridemia. JAMA Cardiol. 2020;5(5): 540-8 PubMed PMID: 32101259. Pubmed central PMCID: PMC7240357 Abbott, Beckman, Siemens, Roche, ET healthcare, Sphingotec, Brava, Quidel, blade, and Novartis outside the submitted work. No other disclosures were reported Epub 2020/02/27. eng.

38. Williams AL, Jacobs SB, Moreno-Macías H, Huerta-Chagoya A, Churchhouse C, Márquez-Luna C, et al. Sequence variants in SLC16A11 are a common risk factor for type 2 diabetes in Mexico. Nature. 2014;506(7486):97-101 PubMed PMID: 24390345. Pubmed Central PMCID: PMC4127086. Epub 2014/01/07. eng.

39. Williams B, Mancia G, Spiering W, Agabiti Rosei E, Azizi M, Burnier M, et al, 2018 ESC/ESH Guidelines for the management of arterial hypertension: The Task Force for the management of arterial hypertension of the European Society of Cardiology and the European Society of Hypertension: The Task Force for the management of arterial hypertension of the European Society of Cardiology and the European Society of Hypertension. J Hypertension. 2018;36(10):1953-2041 PubMed PMID: 30234752. Epub 2018/09/21. eng.

40. Willer CJ, Schmidt EM, Sengupta S, Peloso GM, Gustafsson S, Kanoni S, et al. Discovery and refinement of loci associated with lipid levels. Nat Genet. 2013;45(11):1274-83 PubMed PMID: 24097068. Pubmed Central PMCID: PMC3838666. Epub 2013/10/08. eng.

41. Huerta-Chagoya A, Moreno-Macías H, Fernández-López JC, OrdóñezSánchez ML, Rodríguez-Guillén R, Contreras A, et al. A panel of 32 AIMs suitable for population stratification correction and global ancestry estimation in Mexican mestizos. BMC Genet. 2019;20(1):5 PubMed PMID: 30621578. Pubmed Central PMCID: PMC6323778. Epub 2019/01/10. eng.

42. Price AL, Patterson NJ, Plenge RM, Weinblatt ME, Shadick NA, Reich D. Principal components analysis corrects for stratification in genome-wide association studies. Nat Genet. 2006;38(8):904-9 PubMed PMID: 16862161. Epub 2006/07/25. eng.

43. Purcell S, Neale B, Todd-Brown K, Thomas L, Ferreira MA, Bender D, et al. PLINK: a tool set for whole-genome association and population-based linkage analyses. Am J Hum Genet. 2007;81(3):559-75 PubMed PMID: 17701901. Pubmed Central PMCID: PMC1950838. Epub 2007/08/19. eng.

44. López-Ratón M, Rodríguez-Álvarez M, Cadarso-Suárez C, Gude-Sampedro F. OptimalCutpoints: an R package for selecting optimal Cutpoints in diagnostic tests. J Stat Softw. 2014;061:1-36.

45. R: The R Project for Statistical Computing n.d [cited 2020 July 11]. Available from: http://www.R-project.org

46. Niwa H, lizuka K, Kato T, Wu W, Tsuchida H, Takao K, et al. ChREBP rather than SHP regulates hepatic VLDL secretion. Nutrients. 2018;10(3):321. PubMed PMID: 29518948. Pubmed Central PMCID: PMC5872739. Epub 2018/03/10. eng. https://doi.org/10.3390/nu10030321.

47. lizuka K, Takao K, Kato T, Horikawa Y, Takeda J. ChREBP reciprocally regulates liver and plasma triacylglycerol levels in different manners. Nutrients. 2018; 10(11):1699. PubMed PMID: 30405056. Pubmed Central PMCID: PMC6266805. Epub 2018/11/09. eng. https://doi.org/10.3390/nu10111699.

48. Chow WS, Xu A, Woo YC, Tso AW, Cheung SC, Fong CH, et al. Serum fibroblast growth factor-21 levels are associated with carotid atherosclerosis independent of established cardiovascular risk factors. Arterioscler Thromb Vasc Biol. 2013;33(10):2454-9 PubMed PMID: 23887638. Epub 2013/07/28. eng.

49. Lee Y, Lim S, Hong ES, Kim JH, Moon MK, Chun EJ, et al. Serum FGF21 concentration is associated with hypertriglyceridaemia, hyperinsulinaemia and pericardial fat accumulation, independently of obesity, but not with current coronary artery status. Clin Endocrinol. 2014;80(1):57-64 PubMed PMID: 23278761. Epub 2013/01/03. eng.

50. Akyildiz ZI, Polat S, Yurekli BS, Kocabas GU, Tuluce K, Tuluce SY, et al. Epicardial fat, body mass index, and triglyceride are independent contributors of serum fibroblast growth factor 21 level in obese premenopausal women. J Endocrinol Investig. 2015;38(3):361-6 PubMed PMID: 25312836. Epub 2014/10/15. eng.

51. Borén J, Matikainen N, Adiels M, Taskinen MR. Postprandial hypertriglyceridemia as a coronary risk factor. Clinica chimica acta. Int J Clin Chem. 2014;431:131-42 PubMed PMID: 24508990. Epub 2014/02/11. eng.

52. Hassan M. ANGPLT3: a novel modulator of lipid metabolism. Glob Cardiol Sci Pract. 2017;2017(1):e201706 PubMed PMID: 28971105. Pubmed Central PMCID: PMC5621725. Epub 2017/10/04. eng.

53. Kersten S. Angiopoietin-like 3 in lipoprotein metabolism. Nat Rev Endocrinol. 2017;13(12):731-9 PubMed PMID: 28984319. Epub 2017/10/07. eng.

54. Morelli MB, Chavez C, Santulli G. Angiopoietin-like proteins as therapeutic targets for cardiovascular disease: focus on lipid disorders. Expert Opin Ther Targets. 2020;24(1):79-88 PubMed PMID: 31856617. Pubmed Central PMCID: PMC7169433. Epub 2019/12/21. eng.

55. Adam RC, Mintah IJ, Alexa-Braun CA, Shihanian LM, Lee JS, Banerjee P, et al. Angiopoietin-like protein 3 governs LDL-cholesterol levels through endothelial lipase-dependent VLDL clearance. J Lipid Res. 2020;61(9):127186 PubMed PMID: 32646941. Pubmed Central PMCID: PMC7469887. Epub 2020/07/11. eng

56. Gaudet D, Karwatowska-Prokopczuk E, Baum SJ, Hurh E, Kingsbury J, Bartlett VJ, et al. Vupanorsen, an $\mathrm{N}$-acetyl galactosamine-conjugated antisense drug to ANGPTL3 mRNA, lowers triglycerides and atherogenic lipoproteins in patients with diabetes, hepatic steatosis, and hypertriglyceridaemia. Eur Heart J. 2020; 41(40):3936-45 PubMed PMID: 32860031. Epub 2020/08/30. eng.

57. Chen YQ, Pottanat TG, Siegel RW, Ehsani M, Qian YW, Zhen EY, et al. Angiopoietin-like protein 8 differentially regulates ANGPTL3 and ANGPTL4 during postprandial partitioning of fatty acids. J Lipid Res. 2020;61(8):120320 PubMed PMID: 32487544. Pubmed Central PMCID: PMC7397750. Epub 2020/06/04. eng.

58. Huerta-Chagoya A, Moreno-Macías H, Sevilla-González M, Rodríguez-Guillén R, Ordóñez-Sánchez ML, Gómez-Velasco D, Muñoz-Hernández L, SeguraKato Y, Arellano-Campos O, Cruz-Bautista I, Aguilar-Salinas CA, Tusié-Luna T. Contribution of known genetic risk variants to dyslipidemias and type 2 diabetes in Mexico: a population-based Nationwide study. Genes (Basel). 
2020;11(1):114. PubMed PMID: 31968565. Pubmed Central PMCID:

PMC7016795. Epub 2020/01/24. eng. https://doi.org/10.3390/genes1101

0114.

59. Estrada K, Aukrust I, Bjørkhaug L, Burtt NP, Mercader JM, García-Ortiz H, et al. Association of a low-frequency variant in HNF1A with type 2 diabetes in a Latino population. Jama. 2014;311(22):2305-14 PubMed PMID: 24915262 Pubmed Central PMCID: PMC4425850. Epub 2014/06/11. eng.

60. Martagón AJ, Bello-Chavolla OY, Arellano-Campos O, Almeda-Valdés P, Walford GA, Cruz-Bautista I, et al. Mexican carriers of the HNF1A p.E508K variant do not experience an enhanced response to sulfonylureas. Diabetes Care. 2018:41(8):1726-31 PubMed PMID: 29844095. Epub 2018/05/31. eng.

\section{Publisher's Note}

Springer Nature remains neutral with regard to jurisdictional claims in published maps and institutional affiliations.

Ready to submit your research? Choose BMC and benefit from:

- fast, convenient online submission

- thorough peer review by experienced researchers in your field

- rapid publication on acceptance

- support for research data, including large and complex data types

- gold Open Access which fosters wider collaboration and increased citations

- maximum visibility for your research: over $100 \mathrm{M}$ website views per year

At BMC, research is always in progress.

Learn more biomedcentral.com/submissions 